\title{
ПРАКТИЧЕСКИЕ РЕКОМЕНДАЦИИ ПО ЛЕЧЕНИЮ ГЕРМИНОГЕННЫХ ОПУХОЛЕЙ У МУЖЧИН
}

Коллектив авторов: Трякин А.А., Гладков О.А., Матвеев В.Б., Проценко С.А., Тюляндин С.А., Федянин М.Ю.

DOI: $10.18027 / 2224-5057-2020-10-3 s 2-34$

Ключевые слова: герминогенные опухоли, семинома, несеминома, внегонадные опухоли,

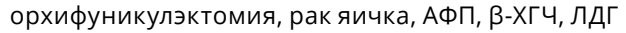

\section{1. КЛАССИФИКАЦИЯ И ОПРЕДЕЛЕНИЕ СТАДИИ}

Свыше $90 \%$ всех герминогенных опухолей у мужчин представлено герминогенными опухолями яичка. Первичные внегонадные опухоли забрюшинного пространства, переднего средостения и ЦНС встречаются значительно реже.

\section{1. Клиническая классификация}

В связи с различными лечебными подходами герминогенные опухоли клинически подразделяются на семиномы и несеминомные опухоли. К последним относят опухоли, содержащие любой несеминомный вариант, а также «чистые» семиномы с повышенным уровнем АФП. Пациенты с семиномой II-III стадии и высоким уровнем $\beta$-ХГЧ (> 1000 мМЕ/мл) имеют более неблагоприятный прогноз, на основании чего рекомендуется их лечить по принципам терапии несеминомных опухолей.

\section{2. Стадирование опухолей яичка}

Стадирование опухолей яичка осуществляется в соответствии с классификацией TNM AJCC / UICC (American Joint Committee on Cancer \& Union for International Cancer Control) 8-го пересмотра (2017 г.) (табл. 1), внегонадных опухолей забрюшинного пространства и средостения, а также опухолей яичка IS, II и III стадий - по классификации IGCCCG (International Germ Cell Cancer Collaborative Group) (табл. 2).

Стадирование опухолей яичка по системе TNM AJCC/UICC 8-го пересмотра (2017г.)

\section{Т - первичная опухоль}

За исключением рTіs и рT4, при которых выполнение орхофуникулэктомии (ОФЭ) для классифицирования не является абсолютно необходимым, степень распространения первичной опухоли определяется после ОФЭ.

Цитирование: Трякин А.А., Гладков О.А., Матвеев В.Б., Проценко С.А., Тюляндин С.А., Федянин М.Ю. Практические рекомендации по лечению герминогенных опухолей у мужчин. Злокачественные опухоли: Практические рекомендации RUSSCO \#3s2, 2020 (том 10)-34 


\section{Критерий рТ}

- $\quad$ рTХ - недостаточно данных для оценки первичной опухоли (без ОФЭ применяется категория рTX)

- рТО - первичная опухоль не определяется (например, гистологически верифицирован рубец в яичке)

- pTis - герминогенная опухоль in situ

- рТ1 - опухоль ограничена яичком и придатком без сосудистой/лимфатической инвазии, опухоль может врастать в белочную, но не во влагалищную оболочку

- рТ2 - опухоль ограничена яичком и придатком, имеется сосудистая/лимфатическая инвазия или опухоль прорастает через белочную оболочку яичка и врастает во влагалищную оболочку

- рТЗ - опухоль распространяется на семенной канатик с наличием или без сосудистой / лимфатической инвазии

- рТ4 - опухоль распространяется на мошонку с наличием или без сосудистой/лимфатической инвазии

\section{N - регионарные лимфатические узлы}

К регионарным относятся забрюшинные и подвздошные лимфатические узлы. Паховые лимфатические узлы являются для опухолей яичка отдаленными и поражаются редко. Однако если у пациента были нарушены нормальные пути лимфооттока вследствие ранее выполненных оперативных вмешательств в паховой области (низведение яичка, грыжесечение и др.), то метастазы в паховых лимфатических узлах в данном случае определяются как регионарные.

\section{Клиническая оценка}

- NX - недостаточно данных для оценки состояния регионарных лимфатических узлов

- $\mathrm{NO}$ - нет признаков поражения метастазами регионарных лимфатических узлов

- $\mathrm{N} 1$ - имеются метастазы в одном или нескольких лимфатических узлах $<2$ см в наибольшем измерении

- $\mathrm{N} 2$ - имеются метастазы в одном или нескольких лимфатических узлах $<5$ см в наибольшем измерении

- N3 - имеются метастазы в лимфатических узлах > 5 см в наибольшем измерении

\section{Патоморфологическая оценка}

- $\quad$ pNX - недостаточно данных для оценки регионарных лимфатических узлов

- $\quad$ pNO - метастазы в регионарных лимфатических узлах отсутствуют

- $\quad$ pN1 - имеются метастазы <2 см в наибольшем измерении с поражением до 5 узлов 
- $\quad$ pN2 - имеются метастазы < 5 см в наибольшем измерении с поражением до 5 узлов или распространение опухоли за пределы узла

- pN3 - метастазы в одном или нескольких лимфатических узлах > 5 см в наибольшем измерении

\section{М - отдаленные метастазы}

- $\mathrm{MX}$ - недостаточно данных для определения отдаленных метастазов

- $\mathrm{MO}$ - нет признаков отдаленных метастазов

- M1 - имеются отдаленные метастазы

- M1а - поражены метастазами нерегионарные лимфатические узлы или легкие

- M1b - имеются другие отдаленные метастазы

\section{S - опухолевые маркеры сыворотки крови}

- SX - невозможна оценка уровня маркеров в сыворотке крови

- $\mathrm{SO}$ - уровень маркеров соответствует норме

- $\mathrm{S1}$ - уровень лактатдегидрогеназы (ЛДг) $<1,5 \times \mathrm{B} Г \mathrm{H}$, хорионического

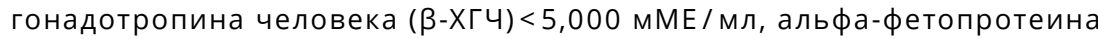
$($ АФП) $<1,000 \mathrm{ME} / \mathrm{мл}$

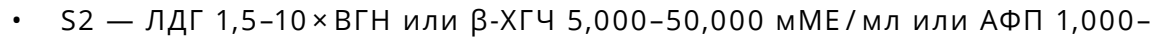
10,000 МЕ / мл.

• $\mathrm{S3}$ - ЛДГ > 10×ВГН или ХГЧ > 50,000 мМЕ/мл или АФП> 10,000 ME/мл

Таблица 1. Группировка по стадиям в соответствии с классификацией TNM8 (2017г.)

\begin{tabular}{|c|c|c|c|c|}
\hline Стадия & Критерий Т & Критерий N & Критерий М & Критерий S \\
\hline Стадия 0 & pTis & No & MO & so \\
\hline Стадия IA & pT1 & No & Mo & So \\
\hline Стадия IB & pT2-4 & NO & MO & SO \\
\hline Стадия IS ${ }^{1}$ & рТ любая & NO & MO & S1-3 \\
\hline Стадия IIA & рТ любая & N1 & MO & SO-1 \\
\hline Стадия IIB & рТ любая & $\mathrm{N} 2$ & MO & So-1 \\
\hline Стадия IIC & рТ любая & N3 & MO & SO-1 \\
\hline Стадия IIIA & рТ любая & Любое N & M1a & So-1 \\
\hline Стадия IIIB & $\begin{array}{l}\text { рТ любая } \\
\text { рТ любая }\end{array}$ & $\begin{array}{l}\text { pN1-3 } \\
\text { Любое N }\end{array}$ & $\begin{array}{l}\text { M0 } \\
\text { M1a }\end{array}$ & $\begin{array}{l}\mathrm{S} 2 \\
\mathrm{~S} 2\end{array}$ \\
\hline Стадия IIIC & $\begin{array}{l}\text { рТ любая } \\
\text { рТ любая } \\
\text { рТ любая }\end{array}$ & $\begin{array}{l}\text { pN1-3 } \\
\text { Любая N } \\
\text { Любая N }\end{array}$ & $\begin{array}{l}\text { M0 } \\
\text { M1a } \\
\text { M1b }\end{array}$ & $\begin{array}{l}\text { S3 } \\
\text { S3 } \\
\text { Любая S }\end{array}$ \\
\hline
\end{tabular}

1 Стадия ISустанавливается у пациентов без признаков регионарных и отдаленных метастазов, у которых после ОФЭ не наблюдается в срок нормализация опухолевых маркеров (АФП или ХГЧ). 
Таблица 2. Прогностические группы при герминогенных опухолях (классификация IGCCCG)

\begin{tabular}{|c|c|}
\hline Несеминома & Семинома \\
\hline \multicolumn{2}{|c|}{ БЛАГОПРИЯТНЫЙ ПРОГНОЗ (56\% пациентов, 5-летняя общая выживаемость - 92\%) } \\
\hline 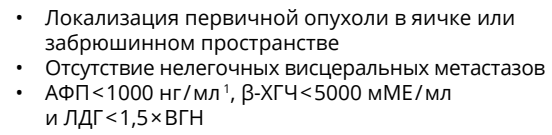 & $\begin{array}{l}\text { - Любая локализация первичной опухоли } \\
\text { - Отсутствие нелегочных висцеральных мета- } \\
\text { стазов } \\
\text { - Нормальный уровень АФП, любые значения } \\
\text { В-ХГЧ и ЛдГ }\end{array}$ \\
\hline \multicolumn{2}{|c|}{ ПРОМЕЖУТОЧНЫЙ ПРОГНОЗ (28\% пациентов, 5-летняя общая выживаемость - 80\%) } \\
\hline 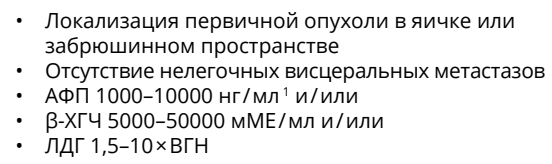 & $\begin{array}{l}\text { · Любая локализация первичной опухоли } \\
\text { · Наличие нелегочных висцеральных метастазов }\end{array}$ \\
\hline \multicolumn{2}{|c|}{ НЕБЛАГОПРИЯТНЫЙ ПРОГНОЗ (16\% пациентов, 5-летняя общая выживаемость - 48\%) } \\
\hline 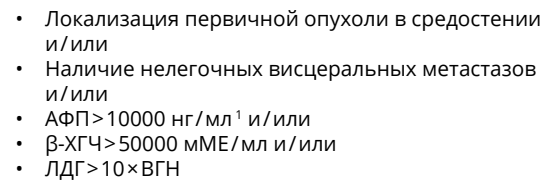 & $\begin{array}{l}\text { Варианта неблагоприятного прогноза для семино- } \\
\text { мы не предусмотрено }\end{array}$ \\
\hline
\end{tabular}

1 Для пересчета уровня АФП из МЕ/мл в нг/мл необходимо значение показателя в МЕ/мл умножить на поправочный коэффичиент 1,21 (например, 1000 МЕ/мл=1210 нг/мл).

\section{2. ДИАГНОСТИКА}

Диагноз устанавливается на основании гистологического исследования яичка после ОФЭ.

Выполнение биопсии рекомендуется больным с первичными опухолями забрюшинного пространства или средостения. При метастазах низкодифференцированного рака без выявленной первичной локализации в забрюшинных и медиастинальных лимфоузлах, легких или печени рекомендуется

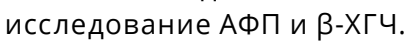

Пациентам в тяжелом общем состоянии, обусловленном обширным метастатическим поражением легких или других органов, по жизненным показаниям рекомендуется немедленное начало ХТ. Диагноз в этих случаях может быть установлен на основании сочетания типичной клинической картины и значимо

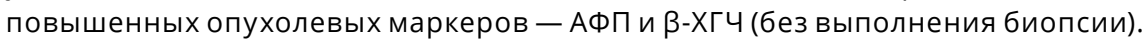

В план обследования входят:

- общий анализ крови, биохимический анализ крови (мочевина, креатинин, электролиты, оценка функции печени), коагулограмма;

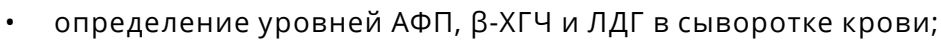

- Узи мошонки; 
- $\quad$ КТ органов грудной клетки, брюшной полости и подвздошных областей с в/в контрастированием;

- УзИ нижней полой вены, подвздошных вен и вен нижних конечностей рекомендуется первичным пациентам с метастазами в забрюшинных лимфоузлах размерами > 3 см и неблагоприятным прогнозом по IGCCCG;

- мониторинг ранее повышенных маркеров каждые 7-10 дней до их нормализации, стабилизации или роста рекомендован у пациентов с І стадией

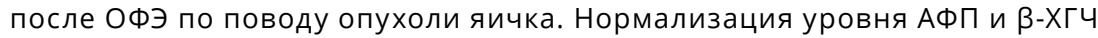
позволяет подтвердить І стадию заболевания, тогда как отсутствие снижения или рост их уровня свидетельствует о наличии метастазов;

- $\mathrm{MPT} \mathrm{(при} \mathrm{отсутствии} \mathrm{возможности} \mathrm{-} \mathrm{КТ)} \mathrm{головного} \mathrm{мозга} \mathrm{с} \mathrm{в/в} \mathrm{контра-}$ стированием у больных с высоким уровнем $\beta$-ХГЧ (свыше 50,000 мME / мл) и / или с множественными метастазами в легких;

- радиоизотопная сцинтиграфия костей скелета выполняется лишь при наличии соответствующих клинических симптомов;

- ПЭТ с целью первичного стадирования не рекомендуется;

- биопсия здорового контралатерального яичка рекомендуется при его атрофии (объем <12 мл) у пациентов молодого возраста (до 30 лет), крипторхизме этого яичка в анамнезе. В этом случае риск внутрипротоковой герминогенной неоплазии неклассифицированного типа (ранее обозначалась как (IS) достигает $33 \%$.

При планировании ХT необходимо обсудить с пациентом риск нарушения фертильности и необходимость криоконсервации спермы. Процедура должна быть выполнена до начала ХТ.

\section{1. Патоморфологическое исследование}

Небольшую опухоль яичка необходимо взять в работу полностью, опухоли до 10 см в наибольшем измерении - 1 блок на каждый 1 см опухоли, при крупных опухолях - не менее 10 блоков. Необходимо взять ткань яичка на границе с опухолью и на отдалении от опухоли, яичко и опухоль с белочной оболочкой, т. к сосудистая/лимфатическая инвазия лучше всего оценивается в перитуморальной зоне, или под белочной оболочкой.

Патоморфологическое описание опухоли должно включать в себя:

1) гистологическое строение опухоли в соответствии с действующей классификацией ВОЗ; желательно указание доли каждого компонента опухоли;

2) размеры опухоли;

3) рТ (наличие или отсутствие лимфоваскулярной инвазии, распространение в rete testis, оболочки яичка, семенной канатик);

4) $\mathrm{pN}$ (с указанием общего числа исследованных и поражённых лимфоузлов, размеров поражения, наличия или отсутствия экстранодального распространения); 
5) наличие поражения края резекции семенного канатика (отрицательный результат также должен быть констатирован);

6) наличие лечебного патоморфоза (если ранее проводилась ХТ).

Рекомендуемый алгоритм обследования представлен на рис. 1, 2.

\section{3. ЛЕЧЕНИЕ}

Учитывая высокую курабельность опухолей и редкость патологии, лечением должен заниматься онколог, имеющий опыт ведения больных герминогенными опухолями. При планировании ХТ необходимо обсудить с пациентом риск нарушения фертильности и необходимость криоконсервации спермы. Процедура должна быть выполнена до начала ХT.

При герминогенных опухолях яичка на первом этапе рекомендуется выполнение ОФЭ. Проведение органосохраняющего лечения возможно по строгим показаниям. Резекция яичка не показана при наличии второго здорового яичка, но может быть рассмотрена как альтернатива ОФЭ у пациентов с синхронными двусторонними опухолями, метахронной опухолью контралатерального яичка, опухолью единственного яичка при нормальном дооперационном уровне тестостерона и размере опухоли менее $30 \%$ от объема органа. С учетом высокой (не менее $82 \%$ ) частоты сопутствующей carcinoma in situ резекция яичка требует обязательного проведения адъювантной локальной лТ яичка в дозе 20 Гр с фракционированием 2 Гр для предотвращения рецидива. Возможно не проводить профилактическую Лт пациентам со II-III стадиями, ранее получивших полный объем ХT.

\subsection{0 стадия (carcinoma in situ)}

При выявлении в яичке carcinoma in situ в отсутствие инвазивного компонента опухоли (например, случайная находка при биопсии по поводу бесплодия) рекомендуется биопсия контралатерального яичка. При наличии carcinoma in situ в одном яичке при наличии второго здорового рекомендуется выполнение ОФЭ или тщательное наблюдение (при отказе от орхофуникулэктомии). При наличии carcinoma in situ обоих яичек или поражении единственного яичка рекомендуется проведение лт яичка (РОД 2 Гр, СОД 20 Гр). В отсутствие лечения в течение 5 лет в 50 \% случаев carcinoma in situ приводит к развитию инвазивной герминогенной опухоли. При выявлении carcinoma in situ при условии тщательного наблюдения возможна отсрочка в лечении до реализации у партнера беременности.

\section{2. Семинома}

При «чистой» семиноме уровень АФП должен быть в пределах нормы. В случае повышенного уровня АФП, несмотря на формальное гистологическое 
заключение «семинома», лечение должно осуществляться, как при несеминомных опухолях. Высокий (свыше 1000 мМЕ / мл) уровень $\beta$-ХГЧ также позволяет заподозрить наличие несеминомного компонента, и данные опухоли также рекомендуется стадировать и лечить по принципам несеминомных.

\subsection{1. Семинома, I стадия (поражение только яичка)}

Факторами повышенного риска развития рецидива являются:

- $\quad$ размер первичной опухоли свыше 4 см (подтверждено не во всех исследованиях);

- опухолевая инвазия стромы яичка (rete testis) (подтверждено не во всех исследованиях).

При отсутствии вышеуказанных факторов риск развития рецидива составляет около 4\% без адъювантной терапии, а при наличии 1-2 факторов - около 15-20\%. Практически все пациенты с рецидивами вылечиваются с помощьюХТ. По этой причине стандартным подходом является динамическое наблюдение, которое должно проводиться по определенному протоколу на протяжении не менее 5 лет. При отсутствии гарантированного наблюдения (невозможность/нежелание) показано проведение одного из следующих вариантов адъювантной терапии, обладающих равной эффективностью:

- лт парааортальных лимфоузлов;

- адъювантная ХТ карбоплатином.

В качестве адъювантной ХT используется один цикл карбоплатина AUC7 (доза В мг $=7 \times[$ клиренс креатинина +25$])$. Клиренс креатинина определяется по формуле Cockroft-Gault.

Адъювантная Лт проводится на парааортальные лимфоузлы (Th10 - L5) в СОД 20 Гр, 10 фракций за 2 нед. Если пациенту ранее выполнялось хирургическое вмешательство на паховой области или мошонке, то поле облучения расширяется до ипсилатеральных пахово-подвздошных областей с СОД 20 Гр, 10 фракций за 2 нед. (так называемая Dogleg лТ). лТ ассоциируется с повышением риска вторичных злокачественных опухолей и в настоящее время становится все менее популярной.

Рекомендуемый алгоритм лечения семиномы представлен на рис. 3.

\subsection{2. Семинома, II-III стадии (диссеминированная)}

\subsubsection{IIA, В стадии (метастазы в забрюшинных лимфоузлах $\leqslant 5$ см)}

- ХТ по аналогии со IIC стадией (см. ниже) или

- лт на парааортальные и ипсилатеральные подвздошные области (Dogleg) по 2 Гр в день, 5 дней в неделю до СОД 30 Гр (при IIA стадии) и 36 Гр (при IIВ стадии).

Рекомендуемый алгоритм лечения семиномы представлен на рис. 3 и 4. 


\subsubsection{IIC-III стадии (метастазы в забрюшинных лимфоузлах >5 см или MI):}

У больных с благоприятным прогнозом по IGCCCG проводится XT 3 курсами ВЕР или 4 курсами ЕР. Роль блеомицина в лечении ранних стадий семиномы точно не определена, поэтому у больных старше 40 лет или при нарушении функции легких в анамнезе можно отказаться от применения блеомицина. Высокий уровень ЛДГ (>2,5×ВГН) является неблагоприятным прогностическим признаком. Пациентам с благоприятным прогнозом и высоким уровнем лдг рекомендовано проведение 4 циклов ХТ (3 курса ВЕР и 1 цикл ЕР). При промежуточном прогнозе по IGCCCG назначаются 4 цикла BEP или 4 цикла PEI (при противопоказаниях к назначению блеомицина).

Лечение внегонадных семином забрюшинного пространства и средостения обычно начинается с XT, выбор режима основывается на принадлежности к прогностической группе по классификации IGCCCG как при IIC-III стадиях опухолей яичка. При выполнении на первом этапе хирургического вмешательства в объеме R0 рекомендовано проведение 2 циклов адъювантной XT по схеме BEP. Рекомендуемый алгоритм лечения семиномы представлен на рис. 3 и 4.

\section{Рецидивы после лучевой терапии}

Больным с рецидивом заболевания после лТ показана ХТ по аналогии с лечением IIC-III стадий.

\subsubsection{3. Оценка эффективности при метастатическом процессе}

Показано КТ органов грудной клетки и брюшной полости, малого таза, определение опухолевых маркеров через 3-4 нед. после окончания всех циклов ХТ.

\subsubsection{4. Лечение и наблюдение больных распространенной семиномой после химиотерапии}

Больные с резидуальной опухолью максимальным размером менее 3 см остаются под наблюдением. Резидуальная опухоль по завершении ХT в подавляющем большинстве случаев представлена некрозом. Кроме того, вследствие особенностей роста семиномы попытка удаления остаточных забрюшинных лимфоузлов лишь в половине случаев бывает радикальной. Проведение лт резидуальной опухоли не улучшает результатов лечения и не рекомендуется. При остаточной опухоли > 3 см рекомендуется ПЭТ-КТ (не ранее, чем через 8 нед. после завершения ХT). При отсутствии накопления радиофармпрепарата рекомендуется наблюдение, при повышенном накоплении - хирургическое лечение. При высоком риске хирургического вмешательства (например, из-за вовлечения магистральных сосудов) рекомендовано повторное выполнение ПЭТ-КТ через 3-4 мес. При снижении/нормализации уровня накопления радиофармпрепарата рекомендуется наблюдение. При сохраняющемся на высоком уровне накоплении - хирургическое вмешательство или открытая биопсия (core биопсия малоинформативна).

Рекомендуемый алгоритм лечения семиномы представлен на рис. 3 и 4. 


\section{3. Несеминомные герминогенные опухоли}

\subsubsection{I стадия (опухоль ограничена яичком)}

После ОФэ без адъювантной терапии прогрессирование заболевания наблюдается у $30 \%$ больных. Для І стадии несеминомных опухолей известен ряд факторов, негативно влияющих на риск рецидива. Важнейшим из них является инвазия опухолью кровеносныхи лимфатических сосудов. При опухолевой инвазии сосудов риск рецидива составляет около $50 \%$, тогда как без инвазии - около $20 \%$. Таким образом, после ОФЭ тактика лечения при I стадии определяется наличием опухолевой инвазии сосудов.

Низкий риск рецидива (отсутствие инвазии). Рекомендуется наблюдение. ОФЭ позволяет излечить 76-88\% больных с І клинической стадией, а у 12-24\% с рецидивом заболевания ранняя диагностика прогрессирования и своевременное начало XТ в подавляющем большинстве случаев приводит к излечению. Только при невозможности или отказе больного от наблюдения в группе низкого риска (отсутствие инвазии сосудов яичка) рекомендуется провести 1 цикл адъювантной ХТ комбинацией ВЕР.

Высокий риск рецидива (наличие опухолевой инвазии сосудов яичка). Рекомендовано проведение 1 цикла ХТ комбинацией ВЕР. Это позволяет достигнуть 5-летней безрецидивной и общей выживаемости равной $97 \%$ и $99 \%$ соответственно. Недостатком такого подхода является тот факт, что, по крайней мере, у $50 \%$ больных проведение адъювантной ХТ является излишним и сопровождается побочными эффектами. Теоретически, один курс ВЕР может обладать поздней токсичностью, но данных, подтверждающих это, пока нет.

При отказе больных от наблюдения или адъювантной ХТ им может быть предложено выполнение профилактической нервосберегающей ЗЛАЭ. Следует помнить, что при этом 50\% больных будут подвергнуты ненужному оперативному вмешательству, которое у 6-8\% больных осложнится ретроградной эякуляцией вследствие повреждения симпатических нервных волокон. Кроме того, выполнение профилактической ЗЛАЭ не предотвратит развитие отдаленных метастазов (в основном, в легких) у $10 \%$ больных.

Рекомендуемый алгоритм лечения несеминомной герминогенной опухоли яичка I стадии представлен на рис. 6.

\subsection{2. ІІА стадия (метастазы в забрюшинных лимфоузлах $<2$ см)}

При нормальных опухолевых маркерах и размерах забрюшинных лимфоузлов по данным КТ до 2 см (ІІА стадия) в 10-20\% случаев метастазы в них при патоморфологическом исследовании не обнаруживаются. Таким образом, выполнение нервосберегающей ЗЛАЭ при IIА стадии позволяет части больных избежать XT. Важнейшим осложнением ЗЛАЭ является развитие ретроградной эякуляции, имеющей место в 3-8\% случаев даже при выполнении нервосберегающей ЗЛАЭ. При рN+в зависимости от степени распространенности 
процесса возможно как наблюдение, так и проведение 2 циклов адъювантной XT по программе EP.

Альтернативой нервосберегающей ЗЛАЭ является выполнение КТ в динамике и проведение при прогрессировании ХТ в соответствии с принадлежностью к той или иной прогностической группе (по IGCCCG).

При повышенных опухолевых маркерах показана ХТ в соответствии с прогнозом по IGCCCG.

\subsection{3. ІІВ стадия (метастазы в забрюшинных лимфоузлах 2-5 см)}

При нормальном уровне маркеров после ОФЭ и бессимптомных малочисленных метастазах до 5 см, локализующихся в одной изолированной зоне, возможно два подхода: 1) выполнение ЗЛАЭ с последующими 2 циклами адъювантной ХТ по программе ЕР; 2) проведение XТ по аналогии с IIC /III стадиями в соответствии с прогнозом по IGCCCG с последующим выполнением ЗЛАЭ при резидуальных метастазах размерами 1 см и более.

\subsubsection{IIC, III стадии (метастазы в забрюшинных лимфоузлах $>5$ см или MI)}

Рекомендована XT в соответствии с прогнозом по классификации IGCCCG.

- Благоприятный прогноз (по IGCCCG): 3 цикла XТ ВЕР или 4 цикла ЕР.

- Промежуточный прогноз (по IGCCCG): 4 цикла XT BEP или 4 курса PEI позволяют добиться 5-летней выживаемости у $80 \%$ больных. Добавление паклитаксела к режиму ВЕР (режим ТВЕР + филграстим) улучшило выживаемость без прогрессирования по сравнению со стандартным ВЕР у пациентов с промежуточным прогнозом, но ценой большей токсичности.

- Неблагоприятный прогноз (по IGCCCG): стандартная ХT включает 4 цикла ВЕР и позволяет обеспечить 5-летнюю выживаемость, равную $50 \%$ (анализ IGCCCG). Отсутствуют убедительные свидетельства того, что другие режимы ХТ или высокодозная ХТ (с последующей трансплантацией костного мозга) улучшают результаты лечения этой группы больных по сравнению со стандартным ВЕР. При противопоказаниях к назначению блеомицина, а также в случае планируемого в будущем хирургического вмешательства на грудной клетке (метастазы в легких, первичная опухоль средостения) вместо режима ВЕР возможно проведение 4 курсов ХT РЕІ. При равной эффективности последняя комбинация является более миелотоксичной.

Рекомендуемый алгоритм лечения несеминомной герминогенной опухоли яичка II-III стадий представлен на рис. 7-9.

\section{4. Лечение особых категорий больных}

\subsection{1. Внегонадные герминогенные опухоли}

При внегонадной локализации опухоли (переднее средостение, забрюшинное пространство) на первом этапе рекомендуется проведение ХТ в соответ- 
ствии с прогнозом по IGCCCG по принципам лечения IIC-III стадии опухолей яичка (см. раздел 3.3.4). Подходы в отношении контроля эффективности терапии и лечения резидуальной опухоли после ХТ соответствуют таковым при гонадной локализации (рис. 12-13).

\subsection{2. Метастатическое поражение головного мозга}

Риск поражения головного мозга повышен у пациентов с множественными

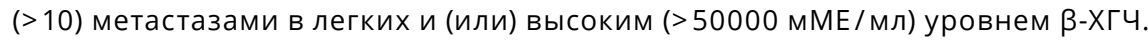
На первом этапе показаны 4 цикла ХТ ВЕР или PEI. При достижении полного эффекта в головном мозге дальнейшее лечение не показано. В связи с редкостью патологии и отсутствием соответствующих исследований значение локальных методов (ЛТ, хирургические вмешательства) в отношении резидуальных метастазов в головном мозге до конца не определено. В большом ретроспективном анализе было показано, что локальные виды лечения (оперативное, лучевое) улучшали выживаемость лишь при добавлении к XT во II-III, но не в І линии.

\subsection{3. Тяжелое общее состояние (по шкале ЕСОG 3-4 балла) первичных пациентов вследствие массивной распространенности опухолевого процесса}

Проведение первого цикла ХТ у таких больных сопряжено с высокой частотой осложнений (распад опухоли, кровотечение, инфекция). Это особенно характерно для метастатической хориокарциномы, когда уровень $\beta$-ХГЧ превышает 50000 мМЕ/мл. По этой причине с целью стабилизации состояния пациента в качестве первого курса может быть проведен редуцированный на 40-60\% цикл ЕР с дробным введением препаратов с последующим профилактическим назначением Г-КСФ. После улучшения состояния, которое обычно отмечается в течение первой недели, проводится весь запланированный объем ХТ в соответствии с прогнозом IGCCCG.

\section{5. Особенности химиотерапии I линии, модификация доз}

Все циклы ХT проводятся каждые 3 нед., считая от первого дня предыдущего курса. Задержка начала очередного курса возможна при наличии в 1-й день планируемого курса:

- инфекционных осложнений или

- нейтропении IV ст. (АЧН $\left.<0,5 \times 10^{9} / л\right)$ или

- тромбоцитопении III ст. (число тромбоцитов <50,0×109/л).

Профилактическое назначение Г-КСФ всем больным, получающим ХТ ВЕР или $E P$, не рекомендуется. При развитии фебрильной нейтропении, нейтропении IV ст. длительностью $>7$ дней или осложненной инфекцией показано профилактическое назначение Г-КСФ при проведении всех последующих циклов ХТ. 


\subsection{1. Схема редүкции доз препаратов при индукционной химиотерапии по программе BEP/EP}

- Если перед началом очередного цикла АЧН $<0,5 \times 10^{9} / л$ или число тромбоцитов $<50,0 \times 10^{9} /$ л, то начало цикла откладывается до восстановления АЧН $>0,5 \times 10^{9} /$ л и тромбоцитов $>50,0 \times 10^{9} /$ л.

- Если перед началом очередного цикла АЧН составляет 0,5-1,0×109/л, а число тромбоцитов - 50,0-100,0×109/л, то используется редукция доз препаратов (табл. 2). Блеомицин не угнетает гемопоэз, в связи с чем его доза не редуцируется при гематологической токсичности.

Таблица 2. Схема редукции доз препаратов в режиме BEP/EP при гематологической токсичности (на основе показателей общеклинического анализа крови на 21-й день от начала предыдущего цикла)

\begin{tabular}{|c|c|c|c|c|c|c|c|c|}
\hline Число тромбо- & \multicolumn{2}{|l|}{$\geq 100,0$} & \multicolumn{2}{|l|}{$75-99$} & \multicolumn{2}{|l|}{$50-74$} & \multicolumn{2}{|l|}{$<50$} \\
\hline $\mathrm{AЧН}^{1}$ (×109/л) & $\begin{array}{l}\text { Этопо- } \\
\text { зид }\end{array}$ & $\begin{array}{l}\text { Циспла- } \\
\text { тин }\end{array}$ & $\begin{array}{l}\text { Этопо- } \\
\text { зид }\end{array}$ & $\begin{array}{l}\text { Циспла- } \\
\text { тин }\end{array}$ & $\begin{array}{l}\text { Этопо- } \\
\text { зид }\end{array}$ & $\begin{array}{l}\text { Циспла- } \\
\text { тин }\end{array}$ & $\begin{array}{l}\text { Этопо- } \\
\text { зид }\end{array}$ & $\begin{array}{l}\text { Циспла- } \\
\text { тин }\end{array}$ \\
\hline$\geq 1,0$ & $100 \%$ & $100 \%$ & $75 \%$ & $100 \%$ & $50 \%$ & $100 \%$ & \multicolumn{2}{|c|}{$\begin{array}{l}\text { Отсрочка до } \\
\text { восстановления } \\
\text { числа тромбоцитов } \\
\geq 50 \times 10^{9} / л\end{array}$} \\
\hline $0,5-0,99$ & $100 \%$ & $100 \%$ & $50 \%$ & $100 \%$ & \multicolumn{2}{|c|}{$\begin{array}{l}\text { Отсрочка до } \\
\text { восстановления } \\
\text { числа тромбоцитов } \\
\geq 75 \times 10^{9} / л\end{array}$} & \multicolumn{2}{|c|}{$\begin{array}{l}\text { Отсрочка до } \\
\text { восстановления } \\
\text { числа тромбоцитов } \\
\geq 50 \times 10^{9} / \text { л }\end{array}$} \\
\hline$<0,5$ & \multicolumn{2}{|c|}{$\begin{array}{l}\text { Отсрочка до вос- } \\
\text { становления АЧН } \\
\geq 0,5 \times 10^{9} / л\end{array}$} & \multicolumn{2}{|c|}{$\begin{array}{l}\text { Отсрочка до вос- } \\
\text { становления АЧН } \\
\geq 0,5 \times 10^{9} / \text { л }\end{array}$} & \multicolumn{2}{|c|}{$\begin{array}{l}\text { Отсрочка до вос- } \\
\text { становления АЧН } \\
\geq 0,5 \times 10^{9} / л\end{array}$} & \multicolumn{2}{|c|}{$\begin{array}{l}\text { Отсрочка до } \\
\text { восстановления } \\
\text { АЧН } \geq 0,5 \times 10^{9} / л \\
\text { и тромбоцитов } \\
\geq 50 \times 10^{9} / л\end{array}$} \\
\hline
\end{tabular}

1Ачн-абсолютное число нейтрофилов

Решение о редукции доз принимается только на основании анализов, полученных за день до начала очередного курса (результаты анализов и модификации доз на предыдущих курсах не используются).

При развитии фебрильной нейтропении или необходимости в отсрочке начала данного курса ХТ показано профилактическое назначение Г-КСФ (филграстима) 5 мкг/кг п/к в 6-15-й дни.

Редукция дозы этопозида на 20-40\% должна быть использована при проведении всех последующих циклов, если несмотря на профилактическое применение Г-КСФ развились следующие состояния:

- нейтропения, осложненная инфекцией 3-4 ст. или

- нейтропения 4 ст. длительностью свыше 7 дней или

- тромбоцитопения 4 ст. длительностью свыше 3 дней или потребовавшая трансфузии тромбоконцентрата. 


\subsection{2. Модификация доз при почечной недостаточности}

При почечной недостаточности, обусловленной компрессией мочеточников, на первом этапе показано наложение нефростомы или стентирование мочеточника. При клиренсе креатинина > 40 мл/мин. доза цисплатина не снижается. При снижении клиренса креатинина <40 мл/мин. цисплатин отменяется. В таком случае возможна замена его на карбоплатин в дозе AUC 5-6. При восстановлении почечной функции цисплатин вводится в дозе, составляющей $75 \%$ от первоначальной. Введение блеомицина прекращается при клиренсе креатинина <40 мл/мин. Для этопозида, имеющего низкую почечную экскрецию, модификация доз в зависимости от почечной функции не предусматривается. Рекомендуемые режимы ХT герминогенных опухолей представлены в табл. 3.

\subsection{3. Профилактика венозных тромбозмболических осложнений}

В связи с высоким риском развития венозных тромбозов пациентам с метастатическим поражением забрюшинных лимфоузлов размерами свыше 5 см, высоким риском по шкале Хорана и (или) наличием центрального венозного катетера в первой линии терапии рекомендуется профилактическое применение антикоагулянтов.

\section{6. Оценка эффекта. Лечение несеминомных опухолей после завершения химиотерапии первой линии}

Перед каждым циклом ХT рекомендуется определять опухолевые маркеры, по окончании ХТ - повторить КТ зон исходного поражения.

Несеминомные опухоли: остаточные образования после окончания XT размерами свыше 1 см рекомендуется удалить.

Оптимальное время выполнения хирургического вмешательства - 4-6 недель после завершения ХТ. В случае поражения нескольких анатомических областей хирургическое лечение начинается с зоны максимального поражения. При выполнении ЗЛАЭ крайне важно выполнение максимально полного удаления всех опухолевых масс. Резекция соседних органов и тканей, включая магистральные сосуды, является оправданной для достижения радикальности. При размерах забрюшинных остаточных опухолевых узлов размером < 5 см предпочтительным является использование модифицированных односторонних трафаретов для ЗЛАЭ, а также по возможности использование нервосберегающих методик для сохранения антеградной эякуляции.

Больные с полным клиническим ответом или наличием в резецированной резидуальной опухоли некроза или тератомы подлежат наблюдению. При наличии в радикально резецированной опухоли жизнеспособной злокачественной опухоли рекомендуется проведение 2 циклов XT по программе ТIP.

Рекомендуемый алгоритм лечения несеминомных опухолей после ХТ представлен на рис. 10. 
Таблица 3. Рекомендуемые режимы химиотерапии герминогенных опухолей

\begin{tabular}{|c|c|c|}
\hline Название режима & Схема введения препаратов & Примечания \\
\hline \multicolumn{3}{|l|}{ Режимы I линии } \\
\hline EP & $\begin{array}{l}\text { Этопозид } 100 \text { мг/м² в/в } 40 \text { мин. в 1-5-й дни } \\
\text { + цисплатин }{ }^{1} 20 \text { мг/м² в/в } 1 \text { час в 1-5-й дни, } \\
\text { каждые } 3 \text { нед. }\end{array}$ & $\begin{array}{l}4 \text { цикла; группа благоприятного } \\
\text { прогноза (при противопоказаниях } \\
\text { к блеомицину) }\end{array}$ \\
\hline BEP & 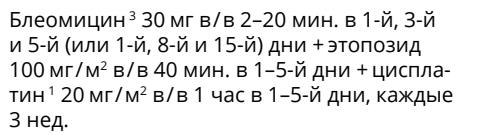 & $\begin{array}{l}3 \text { цикла - при благоприятном про- } \\
\text { гнозе, } 4 \text { цикла - при промежуточ- } \\
\text { ном/неблагоприятном прогнозе }\end{array}$ \\
\hline PEI & 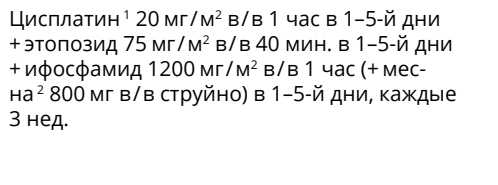 & $\begin{array}{l}4 \text { цикла - при промежуточном/не- } \\
\text { благоприятном прогнозе (как аль- } \\
\text { тернатива ВЕР при противопоказа- } \\
\text { ниях к блеомицину, либо в случаях, } \\
\text { когда после ХТ планируется обшир- } \\
\text { ное хирургическое вмешательство } \\
\text { на грудной клетке) }\end{array}$ \\
\hline \multicolumn{3}{|l|}{ Режимы II линии } \\
\hline VelP & $\begin{array}{l}\text { Винбластин 0,11 мг/кг в/в струйно в 1-й } \\
\text { и 2-й дни + ифосфамид } 1200 \text { мг/м² в/в } 1 \text { час } \\
\text { (+ месна } 80 \% \text { дозы ифосфамида в/в струйно) } \\
\text { в 1-5-й дни + цисплатин }{ }^{1} 20 \text { мг/м² в/в } 1 \text { час } \\
\text { в 1-5-й дни + филграстим } 5 \text { мкг/кг п/к в 6-15-й } \\
\text { дни, каждые } 3 \text { нед. }\end{array}$ & $\begin{array}{l}4 \text { цикла; стандартный режим } \\
\text { ІІ линии }\end{array}$ \\
\hline TIP & 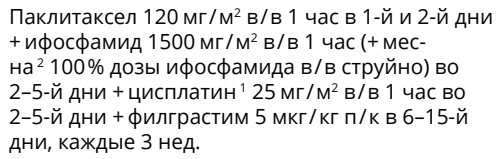 & $\begin{array}{l}4 \text { цикла; стандартный режим } \\
\text { ІІ линии }\end{array}$ \\
\hline \multicolumn{3}{|l|}{ Режимы III линии } \\
\hline TGO & $\begin{array}{l}\text { Паклитаксел } 80 \text { мг/м² в/ в } 1 \text { час в 1-й и 8-й дни } \\
\text { + гемцитабин } 800 \text { мг/м² в/в } 30 \text { мин. в 1-й и 8-й } \\
\text { дни + оксалиплатин } 130 \text { мг/м² в/в } 2 \text { часа в 1-й } \\
\text { день, каждые } 3 \text { нед. }\end{array}$ & 4-6 циклов \\
\hline Gemox & $\begin{array}{l}\text { Гемцитабин } 1000 \text { мг/м² в/в } 30 \text { мин. в 1-й и 8-й } \\
\text { дни + оксалиплатин } 130 \text { мг/м² в/в } 2 \text { часа в 1-й } \\
\text { день, каждые } 3 \text { нед. }\end{array}$ & 4-6 циклов \\
\hline Этопозид р. о. & $\begin{array}{l}\text { Этопозид } 100 \text { мг/сут. внутрь в 1-10 дни, } \\
\text { перерыв } 2 \text { нед. }\end{array}$ & До прогрессирования \\
\hline \multicolumn{3}{|c|}{$\begin{array}{l}\text { Высокодозная химиотерапия с трансплантацией клеток-предшественников гемопоэза } \\
\text { (II-III линии терапии) }\end{array}$} \\
\hline $\mathrm{TI}$ & $\begin{array}{l}\text { Паклитаксел } 200 \text { мг/м² в/в 3-часа, в 1-й день } \\
\text { Ифосфамид } 2000 \text { мг/м² в/в в 1-3-й дни } \\
\text { Месна² в/в струйно в 1-3-й дни } \\
\text { Филграстим } 10 \text { мкг/кг п/к в 4-12-й дни }\end{array}$ & $\begin{array}{l}\text { 1-2 курса, длительность курса - } \\
2 \text { недели (в перерыве - лей- } \\
\text { каферез до сбора CD34+ клеток } \\
\geq 8 \times 10^{6} / \text { кг) }\end{array}$ \\
\hline CE & $\begin{array}{l}\text { Карбоплатин AUC8 в/в в 1-3-й дни } \\
\text { Этопозид } 400 \text { мг/м² в/в 1-3-й дни } \\
\text { Филграстим } 5 \text { мкг/кг п/к в 4-12-й дни } \\
\text { CD34+ клетки } 22 \text { ×106/кг в/в 5-й день }\end{array}$ & $\begin{array}{l}3 \text { курса, длительность курса - } \\
3 \text { недели }\end{array}$ \\
\hline
\end{tabular}


1 Введение цисплатина осуществляется на фоне в/в гидратации 0,9\% р-р хлорида натрия или других изотонических солевых растворов (например, стереофундина), суммарный суточный объем составляет 2,5 л, что необходимо для поддержания диуреза >100 мл/час в прочессе введения чисплатина и в последуюune 3 часа.

2 Месна применяется в суточной дозе, составляющей $60 \%$ от дозы ифосфамида и разделенной на три введения в течение дня: непосредственно перед введением ифосфамида и далее через 4 и 8 часов после начала его инфузии. Возможна замена второго и третьего (через 4 ч и 84) внутривенного введения месны на пероральный. Для этого она применяется внутрь через 2 и 6 часов от начала введения ифосфамида в двукратно большей разовой дозе (40\% от дозы ифосфамида) в виде раствора в Кока-Коле или соке в соотношении от $1: 1$ до $1: 10$

3 Блеомицетина гидрохлорид (изомер А5) и блеомицина сульфат (смесь изомеров А2 и В2) не являются идентичными лекарственными средствами. При использовании блеомицина сульфата в режиме ВЕР используются дозы по 30 мг в 1-й, 3-й, 5-й дни (или в 1-й, 8-й, 15-й дни). При использовании менее изученного блеомицетина гидрохлорида рекомендуется применять меньшие на 30-40\% цикловые дозы препарата, например, по 30 мг в 1-й, 5-й дни.

\section{7. Лечение рецидивов герминогенных опухолей}

Перед началом XT рецидива важно исключить синдром «растущей зрелой тератомы» - появление или увеличение в размерах метастазов на фоне снижающихся / нормальных опухолевых маркеров. В данной ситуации показано хирургическое лечение в виде резекции метастазов или, при невозможности, их биопсия.

Стандартной ХT рецидива являются комбинации на основе ифосфамида, прежде всего - режим TIP, позволяющие добиться длительной выживаемости у $25 \%$ больных с несеминомной опухолью. Альтернативой могут служить режимы PEI (если пациент не получал в I линии терапии этопозид) и VeIP. Обычно проводятся 4 цикла. Не показано преимущество того или иного режима в качестве II линии терапии. Высокодозная XТ (с поддержкой костномозгового кроветворения) по данным единственного рандомизированного исследования не улучшает отдаленных результатов лечения, однако, по данным ряда исследований II фазы, обладает большей эффективностью по сравнению с обычной ХТ и может применяться в центрах, имеющих опыт ее проведения (2 индукционных курса по схеме TI и 3 курса ВДХ по схеме СЕ; табл. 3).

Прогноз при рецидивах семиномы существенно лучше, II линия цисплатинсодержащей ХТ излечивает около 50 \% больных. Применяются те же режимы, что и для несеминомных опухолей. После завершения ХТ рецидива и при наличии остаточной опухоли рекомендовано ее удаление. При обнаружении в удаленных массах жизнеспособной семиномы рекомендуется послеоперационная Лт.

Лечение рецидивов заболевания у пациентов с соматической трансформацией тератомы (в саркому, аденокарциному и т. д.) при нормальных уровнях

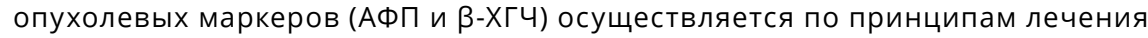
соответствующих морфологических вариантов.

Рекомендуемый алгоритм лечения рецидивов герминогенных опухолей представлен на рис. 11. 


\subsection{1. Хирургическое лечение рецидивов}

Принципы хирургических вмешательств при рецидивах остаются такими же, как и после индукционной ХT: в случае нормализации опухолевых маркеров или персистенции их на низком уровне показано удаление всей резидуальной опухоли. У больных с остаточной опухолью менее 1 см после XT второй и последующих линий риск наличия жизнеспособных злокачественных опухолевых клеток существенно выше, в связи с чем рекомендуется хирургически удалять все остаточные опухолевые массы вне зависимости от размеров. У пациентов с наличием в радикально резецированной опухоли жизнеспособной злокачественной опухоли после второй и последующих линий терапии рекомендуется наблюдение.

В случае роста маркеров, несмотря на проводимую терапию, исчерпанности возможностей XT, локализации опухоли в одной анатомической области целесообразно ее удаление в объеме R0. Этот подход дает шанс спасти около $25 \%$ пациентов, особенно с поздними рецидивами, умеренно повышенным уровнем АФП и забрюшинной локализацией резидуальной опухоли. При бурном прогрессировании с ростом $\beta$-ХГЧ оперативное лечение не показано.

\subsection{2. Лечение поздних рецидивов}

К поздним рецидивам относятся рецидивы, возникшие по прошествии 2 и более лет по окончании ХТ. Их доля от общего числа рецидивов не превышает $5 \%$. Особенностью поздних рецидивов является низкая чувствительность к XT, что позволяет рекомендовать в случае потенциально резектабельных опухолей на первом этапе выполнять хирургическое лечение даже в случае повышенных маркеров. При невозможности радикального удаления опухоли и повышенных маркерах необходимо начинать XT II линии с последующим выполнением операции.

\section{4. НАБЛЮДЕНИЕ}

\section{1. Наблюдение при I стадии несеминомы с динамическим наблюдением (химиотерапия не проводилась)}

Рекомендован следующий график наблюдения:

- физикальный осмотр, опухолевые маркеры - ежемесячно в первый год, каждые 2 мес. - во второй год, каждые 3 мес. - в третий год, каждые 4 мес. - в четвертый год, каждые 6 мес. - в пятый год, далее - ежегодно;

- УзИ органов брюшной полости, забрюшинного пространства и паховоподвздошных областей - каждые 2 мес. в первый год, каждые 3 мес. - во второй год, каждые 4 мес. - в третий и четвертый годы, далее ежегодно;

- рентгенография органов грудной клетки выполняется на каждом втором визите. 


\section{2. Наблюдение за пациентами после химиотерапии, а также при семиноме I стадии}

Рекомендован следующий график наблюдения:

- физикальный осмотр, опухолевые маркеры, УзИ органов брюшной полости, забрюшинного пространства и пахово-подвздошных областей - каждые 2-3 мес. в первый год, каждые 3 мес. - во второй год, затем - каждые 4 мес. в третий и четвертый годы, раз в полгода - в пятый год и далее ежегодно;

- рентгенография органов грудной клетки - на каждом втором визите. 

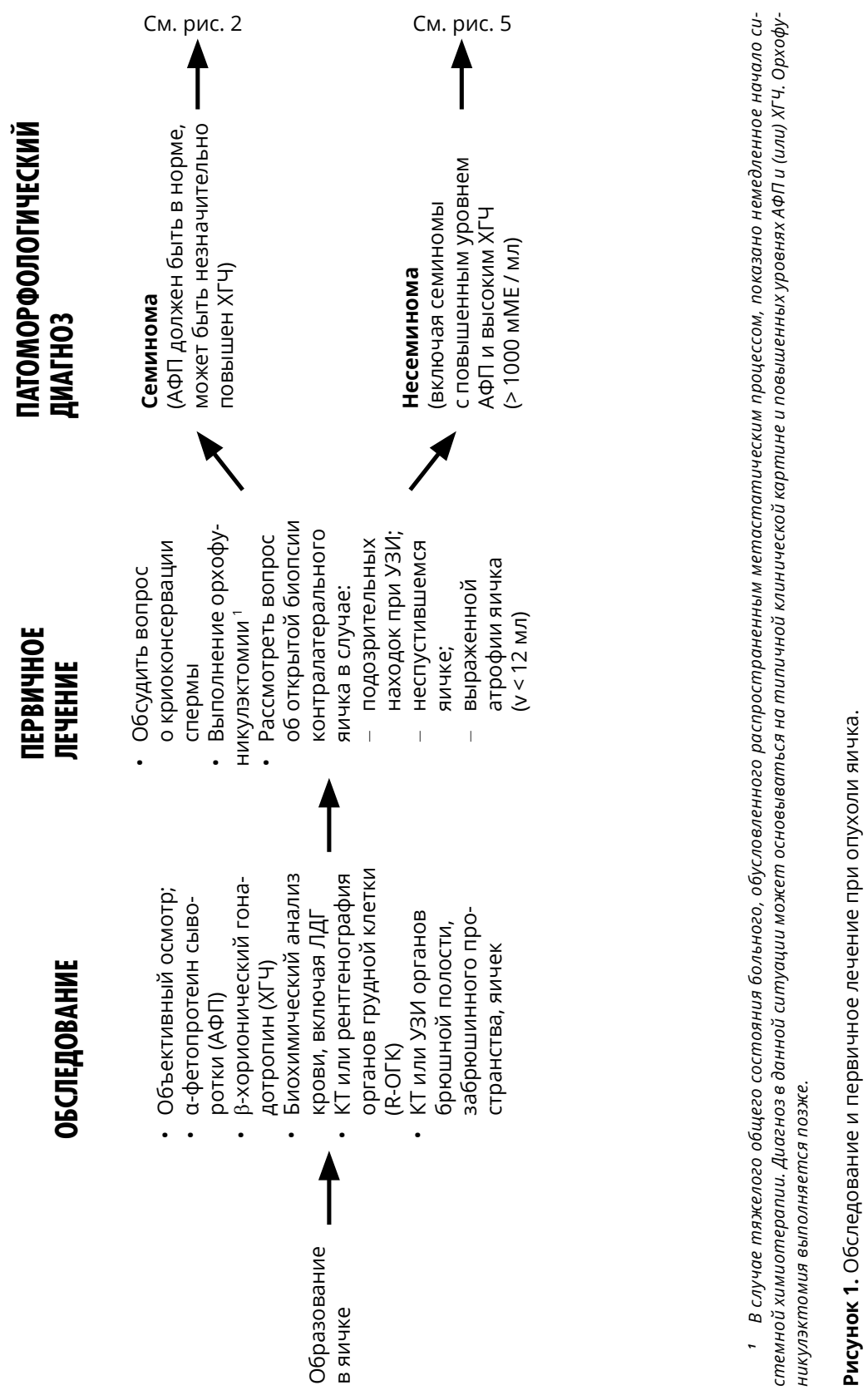
См. pис. 3
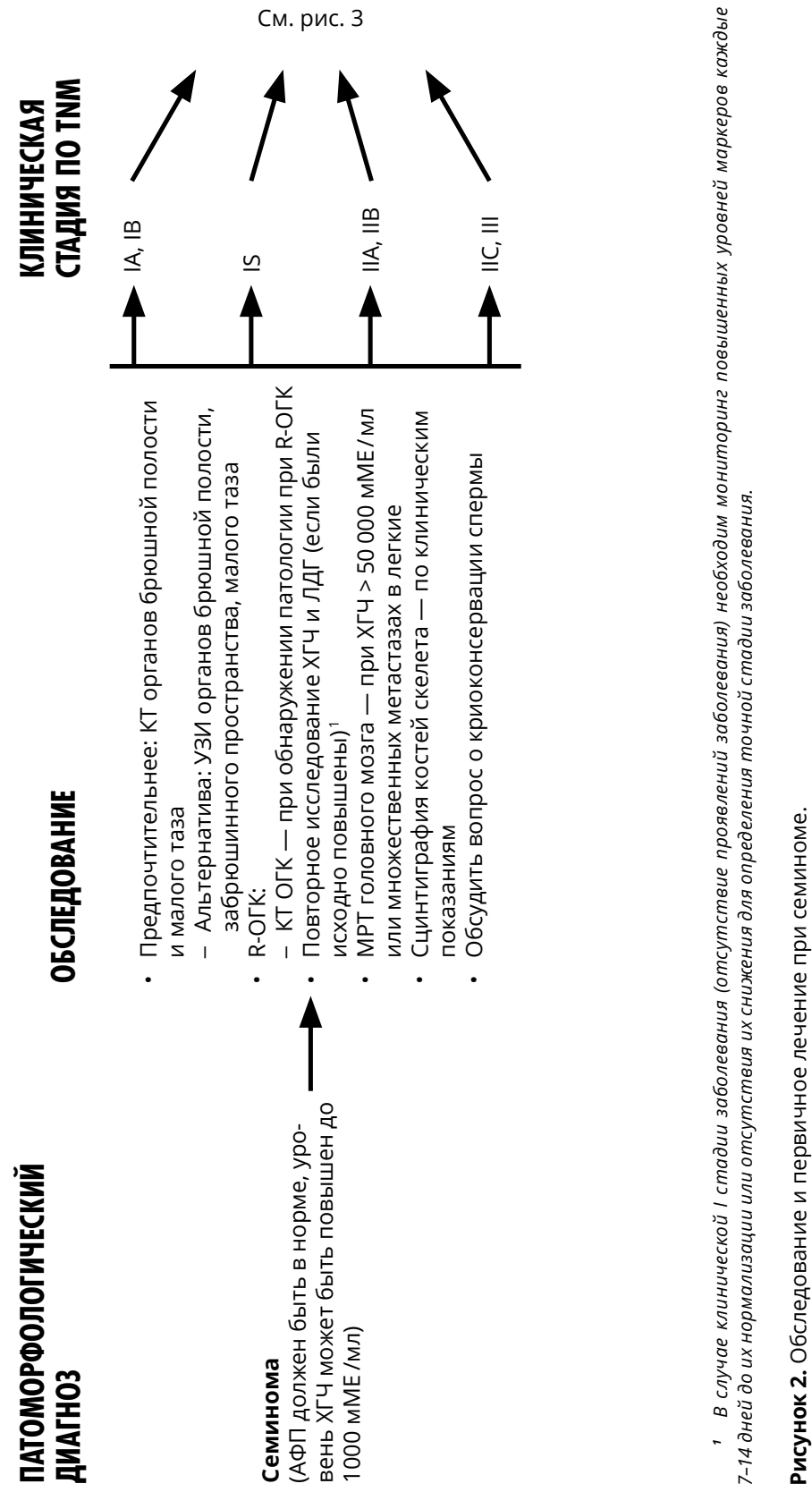

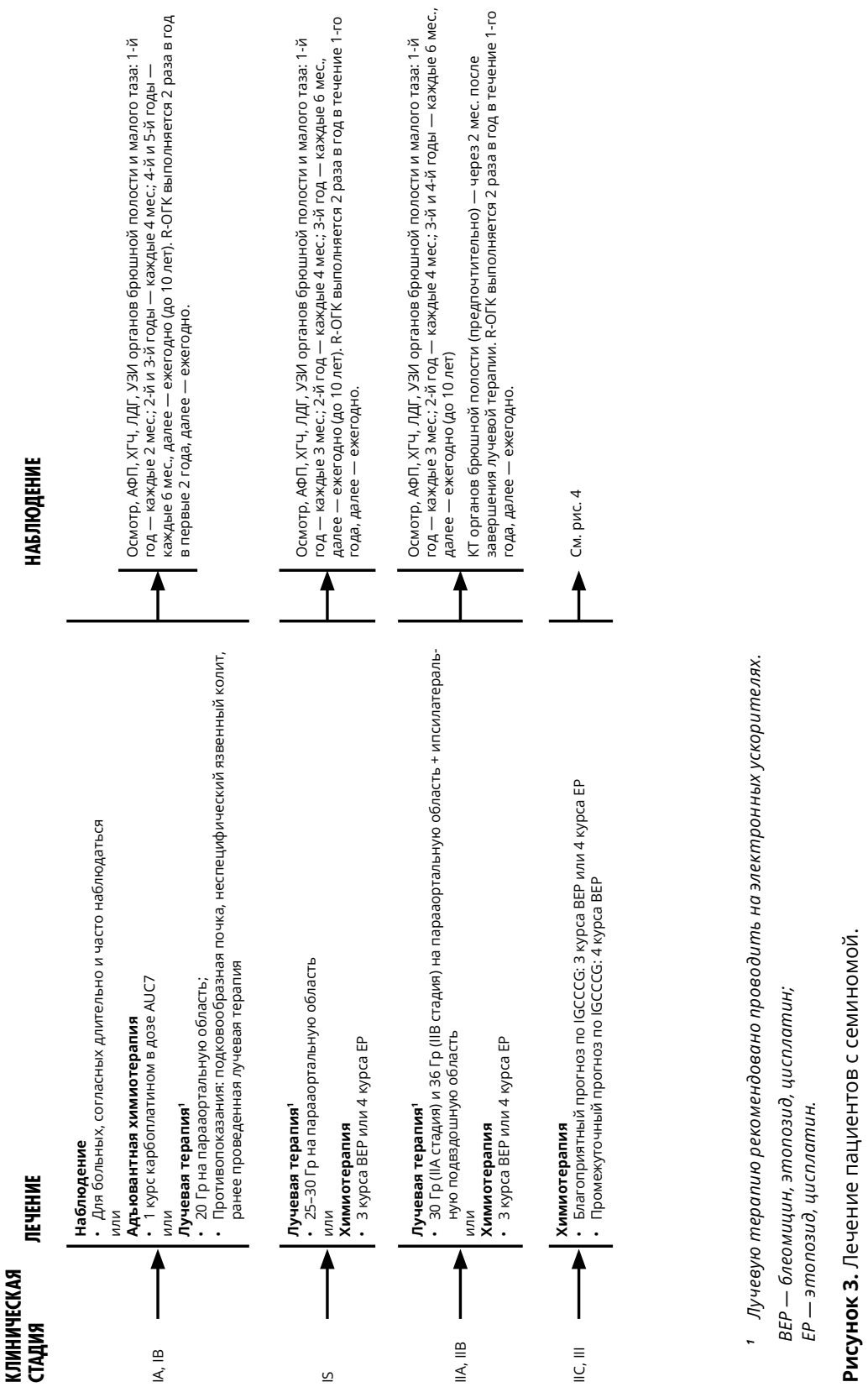

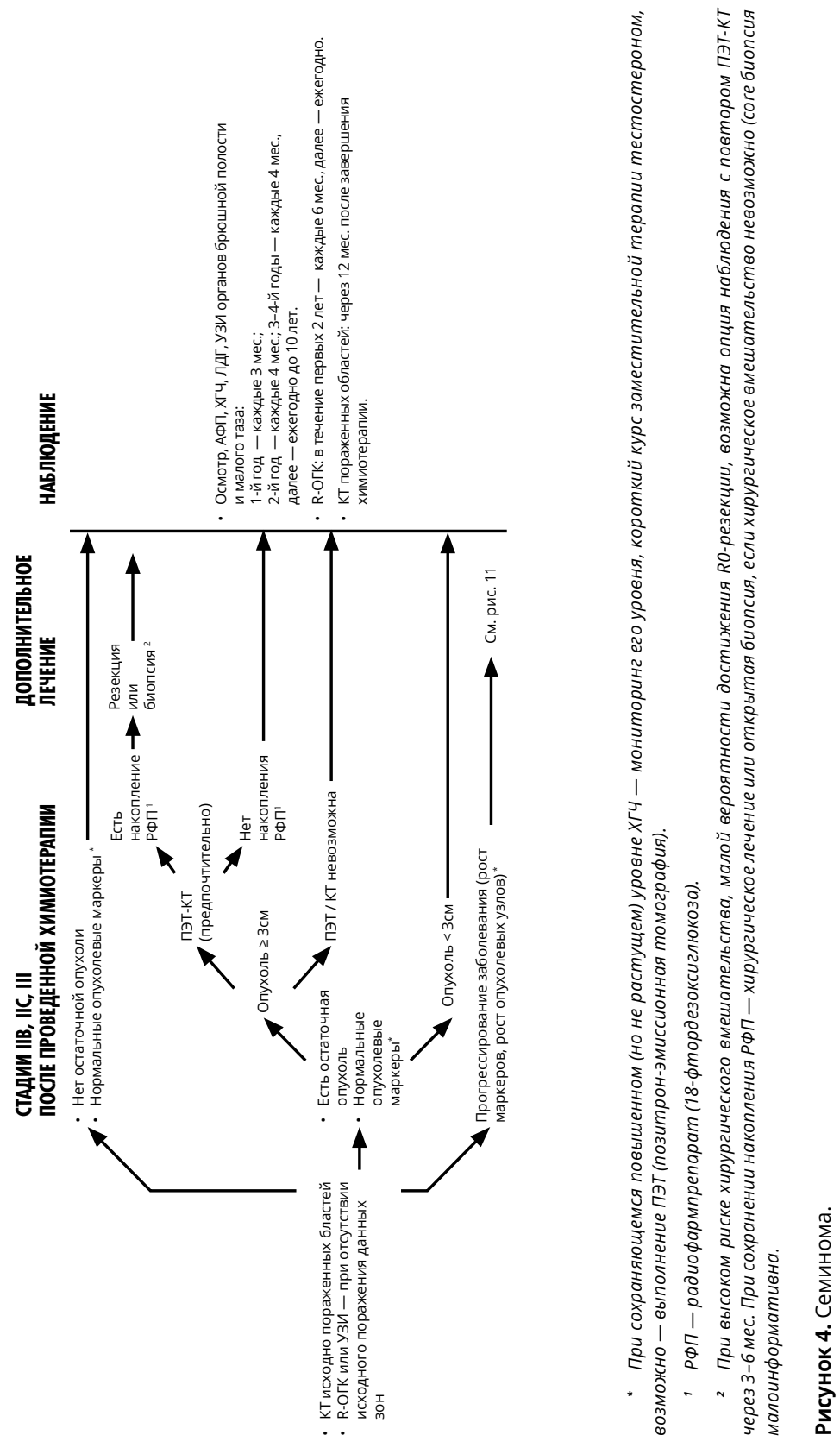

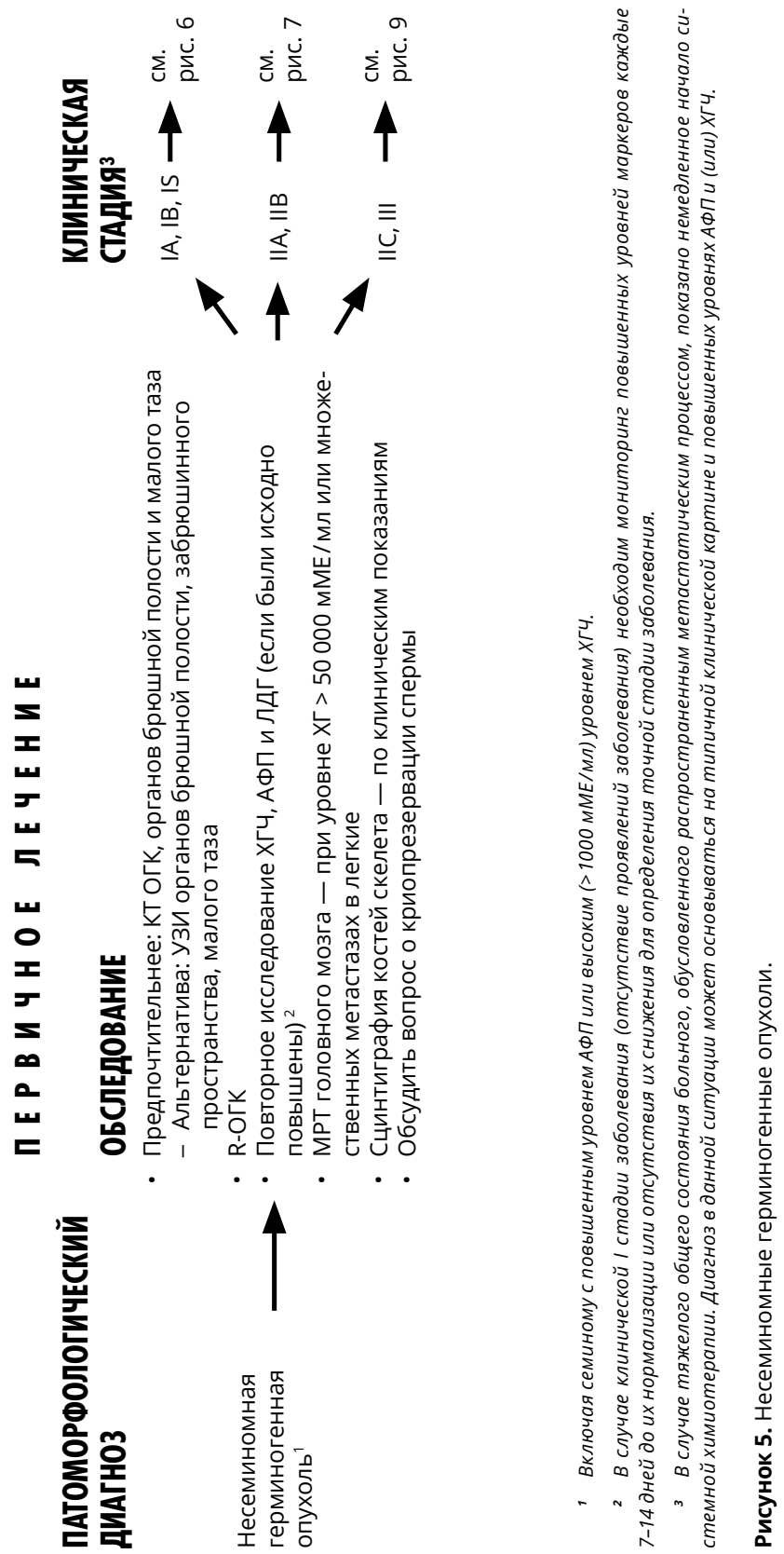


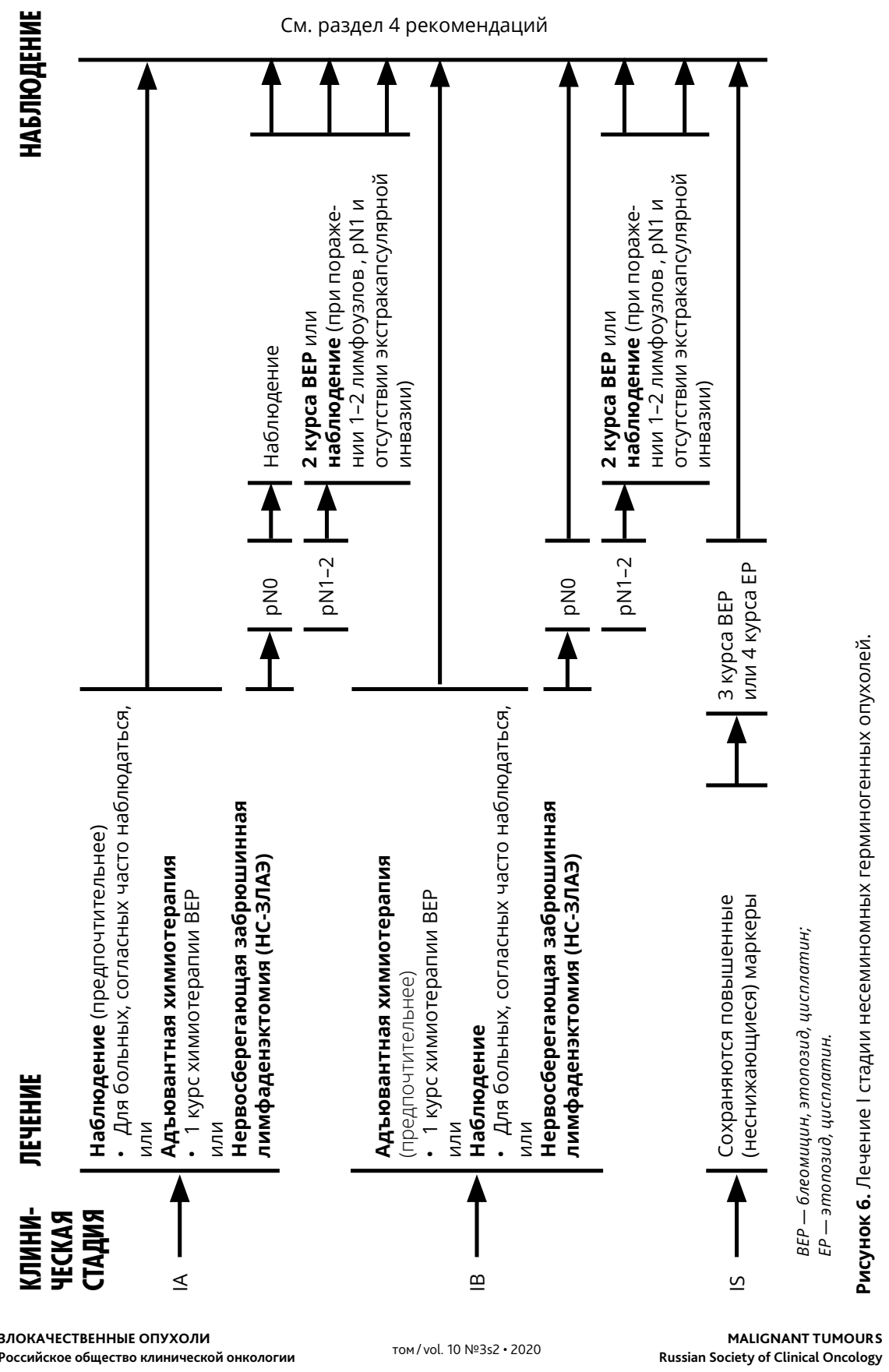



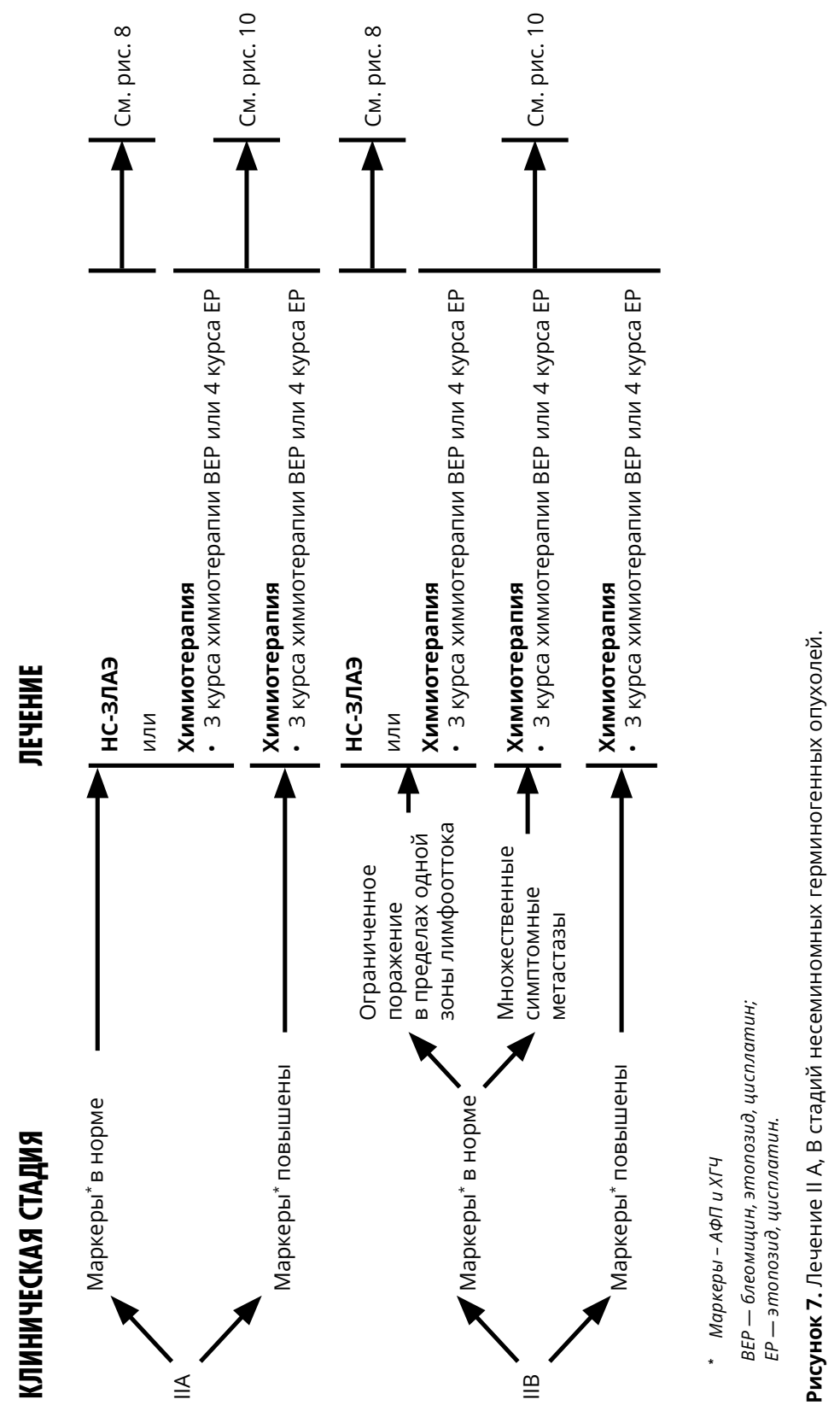

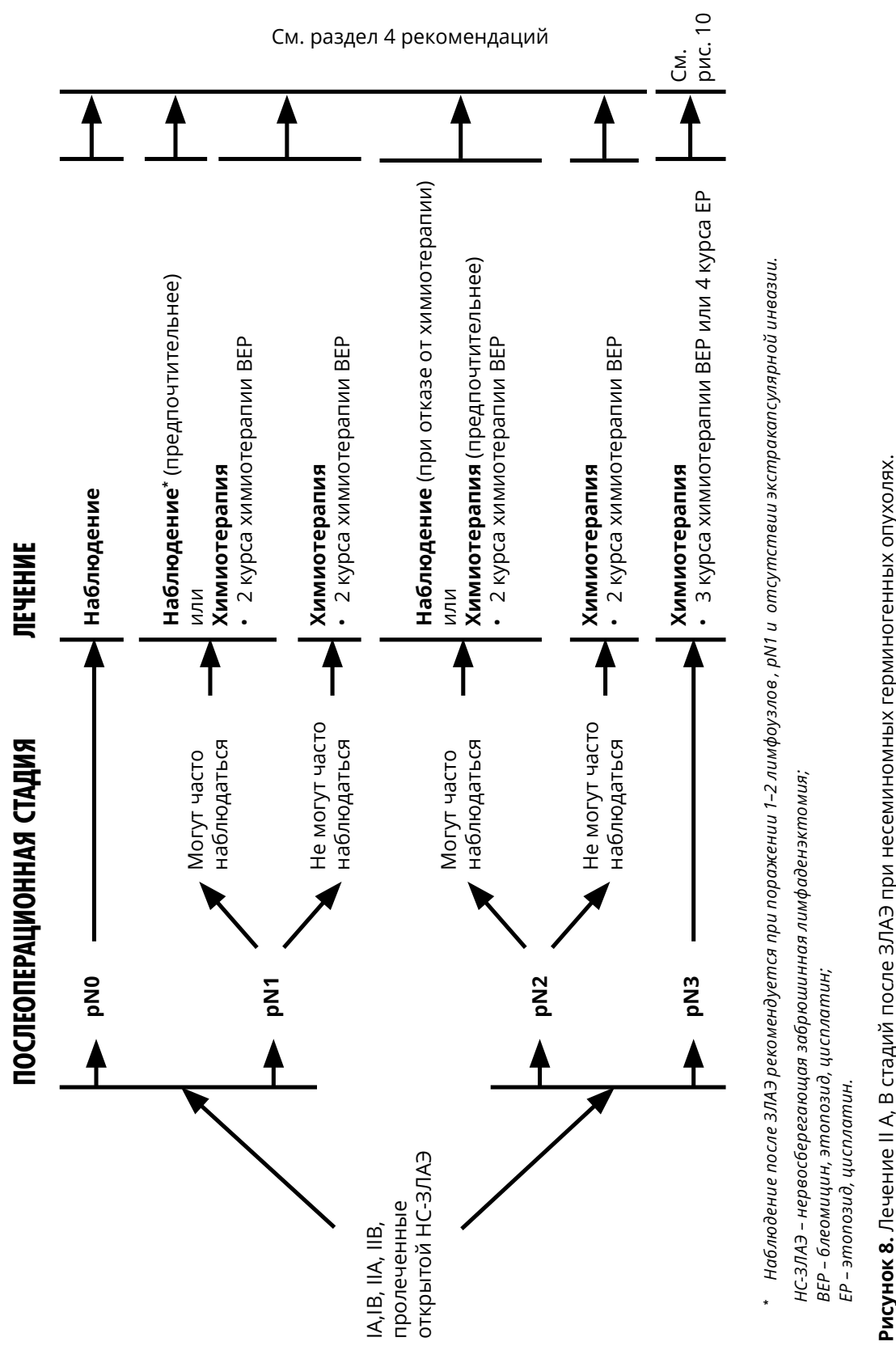

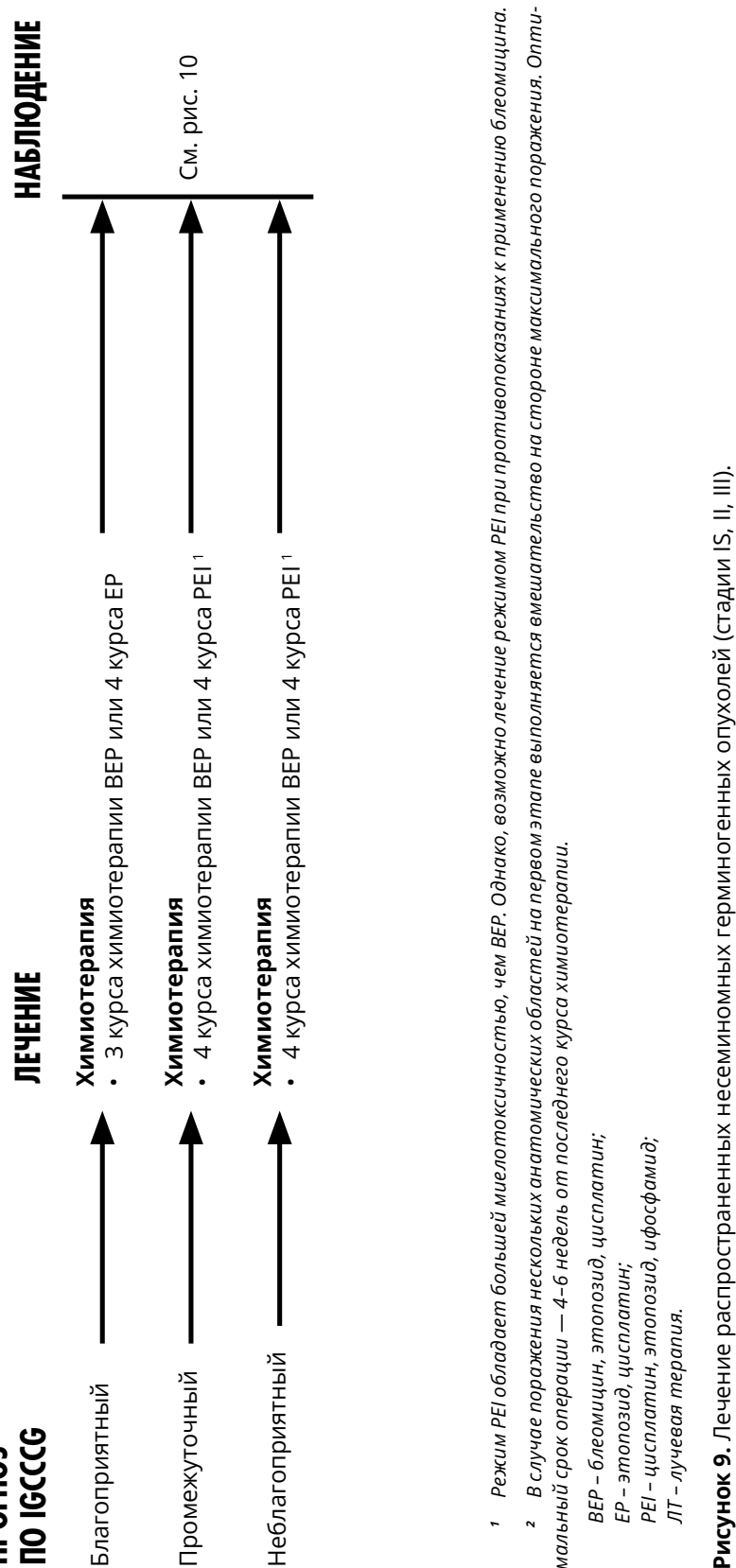

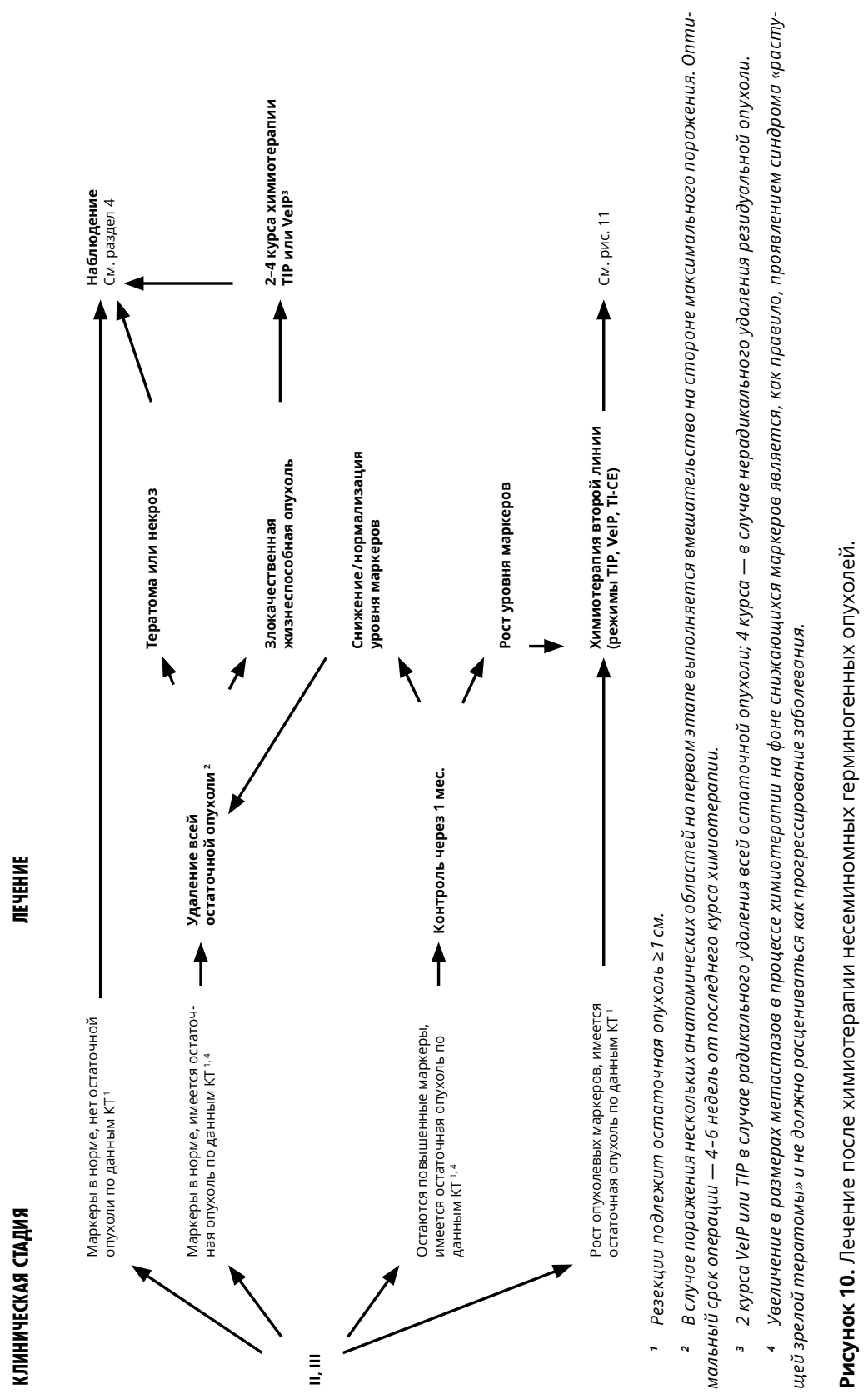


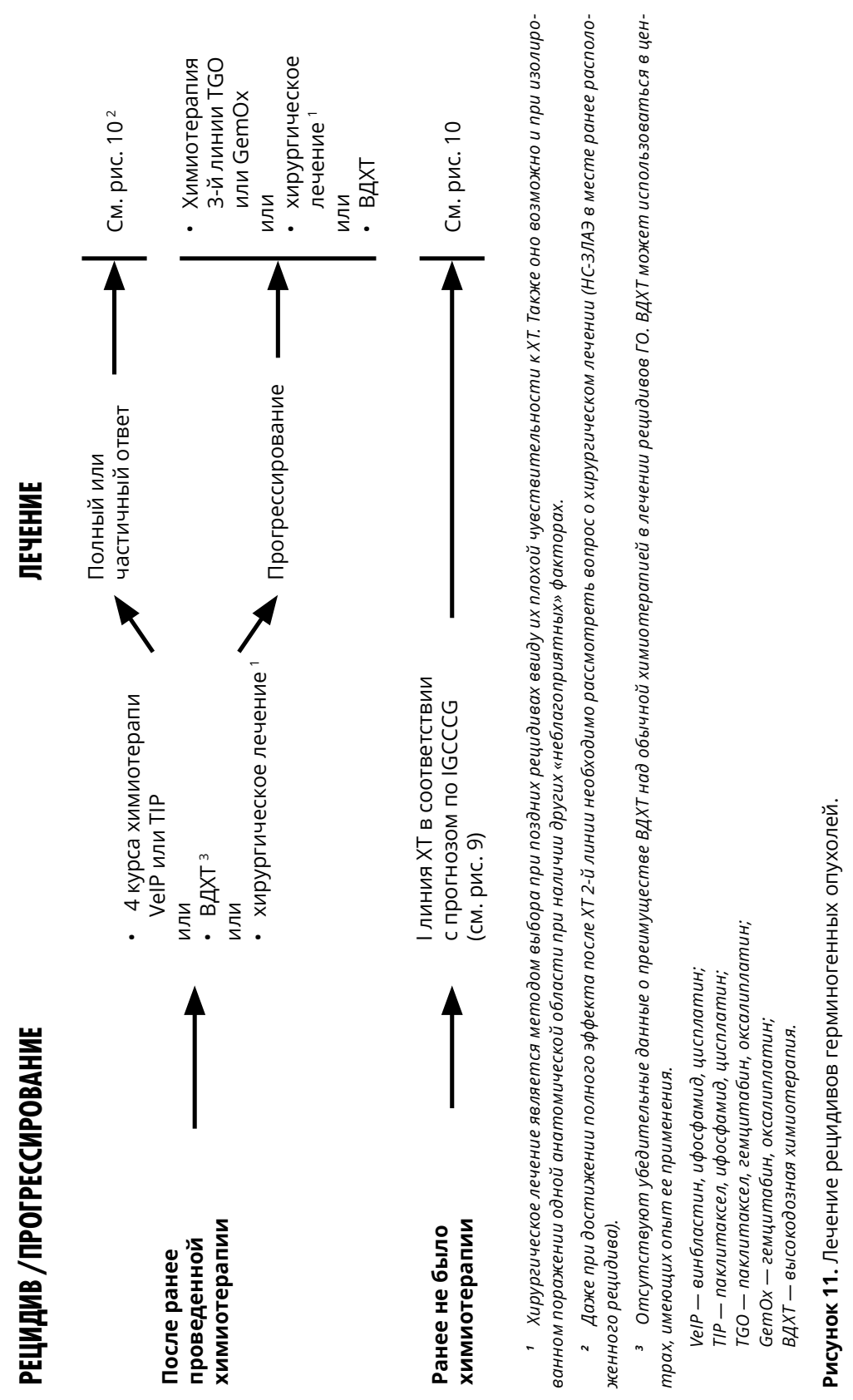


См. рис. 13
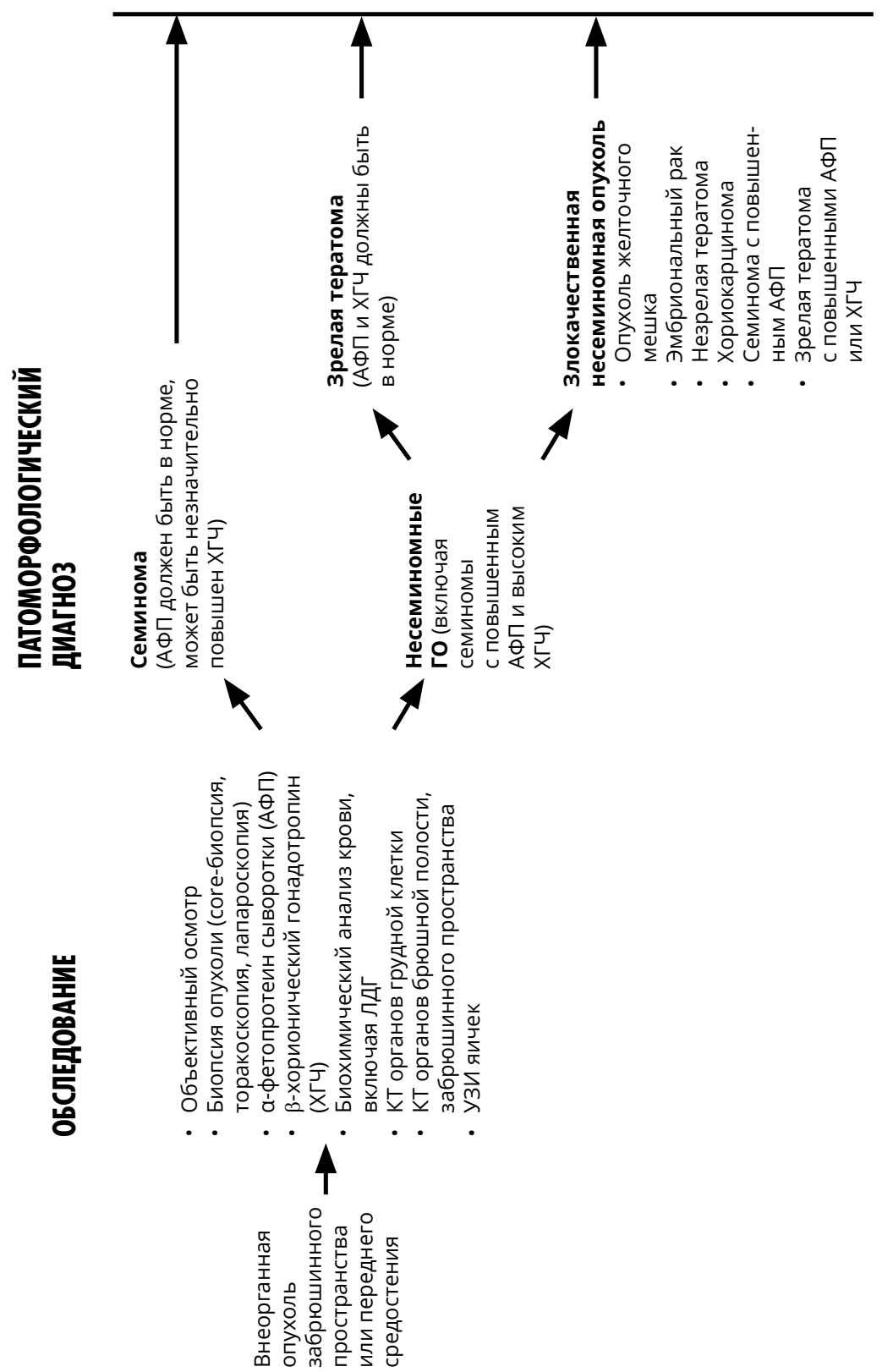


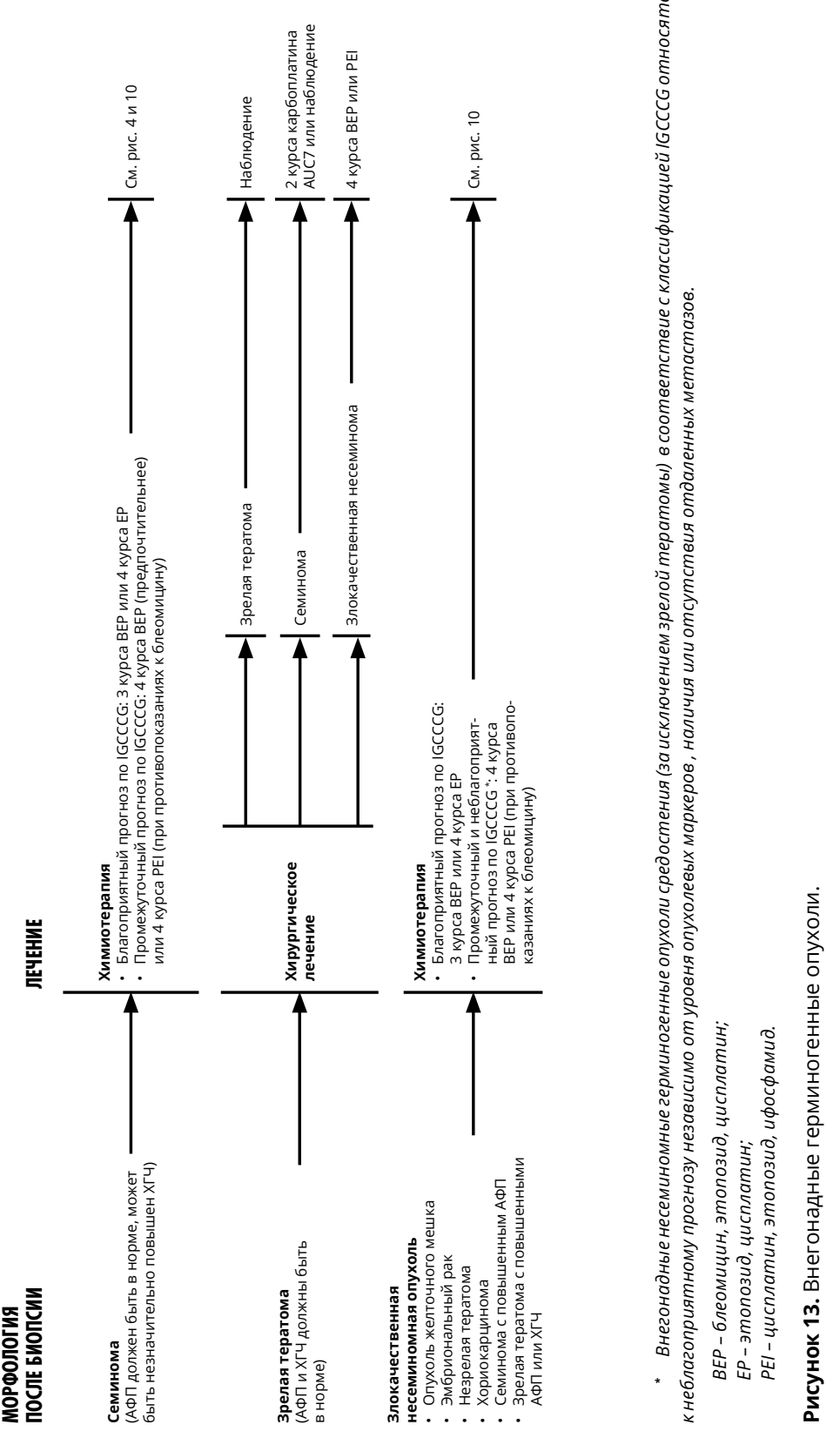

